\title{
Prevention of Hospital-acquired Pressure Ulcers in Patients with Prone Ventilation: A Retrospective Observational Study
}

\author{
Shivangi Mishra ${ }^{1}$, Padmakumar V Arayamparambil ${ }^{2}$, Garud S Chandan ${ }^{3}$, Pooja P Sarada ${ }^{4}$, Megha Sharma ${ }^{5}$
}

\begin{abstract}
Aim: Prone positioning improves oxygenation in patients with hypoxic respiratory failure. A pressure ulcer is a disturbing complication of prone positioning. The use of air mattresses and soft silicone dressing reduces the incidence of pressure ulcers in supine patients and prone intraoperative cases. We have compared the effect of two different strategies on the incidence of hospital-acquired pressure ulcers in patients undergoing prone ventilation for hypoxic respiratory failure.

Materials and methods: We retrospectively analyzed the records of patients who underwent prone ventilation for hypoxic respiratory failure. Patients were divided into groups based on the hospital-acquired pressure ulcer prevention strategy used for prone patients. Patients in group $\mathrm{S}$ (Standard) were prone to the use of pillow support, headrest, and gel pads for pressure areas, while those in group O (Observation) were prone to air mattress along with soft silicone dressing and gel pads for pressure areas. The primary outcome was the incidence of pressure ulcers in both groups. The secondary outcomes were hemodynamic changes, oxygenation, and ventilatory parameters.

Results: A total of 40 patients were included in the study, with equal distribution of 20 patients in each group. The incidence of hospital-acquired pressure ulcers was lower in group $\mathrm{O}$ as compared to group S ( 15 vs $25 \%, p=0.35$ ). No difference was seen in oxygenation, ventilation, or hemodynamic parameters.

Conclusion: Use of air mattress and soft silicone dressing instead of pillow supports and headrest reduces the incidence of pressure ulcers in patients with prone ventilation ( 15 vs $25 \%, p=0.35$ ), which, in our opinion, is clinically significant. Albeit, there is no statistical difference in our study, we believe that a larger, well-designed, prospective study will show clinical and statistical difference. Reduced incidence of pressure ulcers will prevent facial scars, improves patient comfort, and will significantly contribute to better patient outcomes.
\end{abstract}

Keywords: Hypoxic respiratory failure, Intensive care, Pressure ulcer, Prone ventilation, Retrospective study.

\section{Resumen}

Objetivo: La posición en decúbito prono mejora la oxigenación en pacientes con insuficiencia respiratoria hipóxica. Una úlcera por presión es una complicación inquietante de posicionamiento prono. El uso de colchones de aire y apósitos de silicona suave reduce la incidencia de úlceras por presión en pacientes en decúbito supino y prono. Casos intraoperatorios. Hemos comparado el efecto de dos estrategias diferentes sobre la incidencia de úlceras por presión adquiridas en el hospital en pacientes someterse a ventilación en decúbito prono por insuficiencia respiratoria hipóxica.

Materiales y métodos: Analizamos retrospectivamente los registros de los pacientes que fueron sometidos a ventilación en decúbito prono por insuficiencia respiratoria hipóxica. Los pacientes se dividieron en grupos según la estrategia de prevención de úlceras por presión adquirida en el hospital utilizada para pacientes en decúbito prono. Pacientes en grupo Los S (estándar) eran propensos al uso de almohadas, reposacabezas y almohadillas de gel para las áreas de presión, mientras que los del grupo O (observación) eran propensos al colchón de aire junto con un apósito de silicona suave y almohadillas de gel para las áreas de presión. El resultado primario fue la incidencia de úlceras por presión en ambos grupos. Los resultados secundarios fueron cambios hemodinámicos, oxigenación y parámetros ventilatorios.

Resultados: Se incluyó en el estudio un total de 40 pacientes, con una distribución igual de 20 pacientes en cada grupo. La incidencia de enfermedades adquiridas en el hospital Las úlceras por presión fueron menores en el grupo O en comparación con el grupo S (15 vs $25 \%$, $p=0.35$ ). No se observaron diferencias en oxigenación, ventilación o parámetros hemodinámicos.

Conclusión: El uso de colchón de aire y vendaje de silicona suave en lugar de soportes de almohada y reposacabezas reduce la incidencia de úlceras por presión en pacientes con ventilación en decúbito prono ( $15 \mathrm{vs} 25 \%, p=0.35$ ), lo que, en nuestra opinión, es clínicamente significativo. Aunque no hay diferencia estadística en nuestro estudio, creemos que un estudio prospectivo más amplio y bien diseñado mostrará diferencias clínicas y estadísticas. Incidencia reducida de la presión Las úlceras evitarán las cicatrices faciales, mejorarán la comodidad del paciente y contribuirán significativamente a mejorar los resultados del paciente.

Palabras clave: Insuficiencia respiratoria hipóxica, Cuidados intensivos, Úlcera por presión, Ventilación en decúbito prono, Estudio retrospectivo. Panamerican Journal of Trauma, Critical Care \& Emergency Surgery (2020): 10.5005/jp-journals-10030-1296

\section{INTRODUCTION}

Prone positioning is an accepted method for improving oxygenation in patients with moderate-to-severe acute respiratory distress syndrome presenting with hypoxic respiratory failure. ${ }^{1}$ Especially in the current pandemic of coronavirus disease-2019, prone ventilation is a recommended method to improve oxygenation. A pressure ulcer is one of the most disturbing complications which develops

\footnotetext{
${ }^{1-5}$ Department of Critical Care Medicine, Fortis Hospital, Bengaluru, Karnataka, India
}

Corresponding Author: Shivangi Mishra, Department of Critical Care Medicine, Fortis Hospital, Bengaluru, Karnataka, India, Phone: +91 9999873965, e-mail: shivangivatsa@gmail.com

How to cite this article: Mishra S, Arayamparambil PV, Chandan GS, et al. Prevention of Hospital-acquired Pressure Ulcers in Patients with 
as a result of proning. ${ }^{2}$ The incidence of pressure ulcer in prone patients is around $20 \%$ compared to $14 \%$ in supine patients. ${ }^{3}$

Multiple studies have used different strategies for the prevention of pressure ulcers in patients with prone ventilation. ${ }^{4-8}$ The use of air mattresses and soft silicone dressing for pressure points is associated with a reduced incidence of pressure ulcers in supine ventilated patients. ${ }^{9,10}$ However, none of these studies have compared the effect of different strategies on the incidence of hospital-acquired pressure ulcers in patients undergoing prone ventilation. So, the present study was done to compare the effect of two different strategies on the incidence of hospital-acquired pressure ulcers in patients undergoing prone ventilation for hypoxic respiratory failure.

\section{Materials and Methods}

This is a retrospective, observational, and comparative study conducted in the Department of Critical Care Medicine at Fortis Hospital, Bannerghatta Road, Bengaluru. In accordance with the declaration of Helsinki, ethical approval was obtained from the institutional ethics committee. Records of patients admitted to the Medical Intensive Care Unit from January 2017 to December 2019 were reviewed. Patients above 18 years of age who underwent prone ventilation for hypoxic respiratory failure were included in the study. Patients with preexisting hospital-acquired pressure ulcers shifted from other hospitals with previous episodes of proning and those with incomplete records were excluded from the study. The patients were divided based on hospital-acquired pressure ulcer prevention strategies used for proning. Group S (Standard) included patients prone with pillow support for chest and pelvis, headrest along with eye protection and gel-pads for elbow and knee. Group $\mathrm{O}$ (Observation) included patients prone on an alternating pressure air mattress, with protective covering for eyes with a sponge, covering of bony prominences of face and chest with Mepilex ${ }^{\circledast}$ Border (Mölnlycke Health Care, Gothenburg, Sweden) silicone dressing and gel-pads for elbow and knee. Headrest and chest and pelvis pillow support was not used in group O. Data were collected for demographics, Braden risk score, a total duration of proning, development of hospital-acquired pressure ulcers with stage, and location were collected. The staging was based on classification by the National Pressure Ulcer Advisory Panel System. ${ }^{11}$ The worst stage of pressure ulcer documented during the period of proning involving face and chest was recorded. Oxygenation, ventilation, and hemodynamic parameters before proning; 30 minutes after proning, and 2 hours after supination were collected. The outcome in terms of all-cause 28-day mortality was collected.

\section{Statistical Analysis}

The analysis was done using SPSS statistics version 26. The groups were compared using Chi-square test for categorical variables and $t$ test for continuous variables. Continuous variables at different time points were compared between the two groups using repeated measures of analysis of variance (ANOVA). The $p$ value $<0.05$ was considered statistically significant.

\section{Results}

A total of 46 patients underwent prone ventilation for hypoxic respiratory failure over a period of 3 years from January 2017 to December 2019. Of these, six patients were excluded because of incomplete records and episode of proning conducted in outside hospitals. A total 40 patients were included in the study, of which
Prone Ventilation: A Retrospective Observational Study. Panam J Trauma Crit Care Emerg Surg 2020;9(3):198-201.

Source of support: Nil

Conflict of interest: None

20 received proning with standard strategy (group S) and 20 received proning with observation strategy (group 0 ).

The mean age of patients requiring prone ventilation for hypoxic respiratory failure was $45 \pm 15$ years. A male preponderance was seen in the patient requiring prone ventilation. Both the groups were comparable in demographic features (Table 1). H1N1 infection was the most common cause of hypoxic respiratory failure in both the groups. Other causes of hypoxic respiratory failure included influenza A pneumonia, bacterial pneumonia, pancreatitis, and postoperative cases. The average Braden risk score was $12.7 \pm 3.0$ in group $S$ and $12.6 \pm 4.3$ in group $O(p=0.06)$. Though most of the patients required only one cycle of proning, the maximum cycles of proning required were 7 in group $S$ vs 11 in group $O$. This might have caused a higher average total duration of proning in group O compared with group S (51.4 vs 45.7), though the difference was not statistically significant $(p=0.98)$ (Table 1 ).

The primary outcome, which is the incidence of hospitalacquired pressure ulcers was higher in group $S$ compared with group $\mathrm{O}$, though it did not reach statistical significance ( $25 \mathrm{vs}$

Table 1: Demographic and clinical characteristics

\begin{tabular}{|c|c|c|c|c|}
\hline \multicolumn{2}{|l|}{ Parameter } & $\begin{array}{l}\text { Group S } \\
(n=20)\end{array}$ & $\begin{array}{l}\text { Group O } \\
(n=20)\end{array}$ & $p$ value \\
\hline \multicolumn{2}{|l|}{ Age $($ mean $\pm S D)$} & $46.4 \pm 13.6$ & $44.3 \pm 16.6$ & 0.2 \\
\hline \multirow[t]{2}{*}{ Sex, $n(\%)$} & Male & $12(60)$ & $11(55)$ & 0.5 \\
\hline & Female & $8(40)$ & $9(45)$ & \\
\hline \multirow[t]{3}{*}{ Diagnosis, $n(\%)$} & $\mathrm{H} 1 \mathrm{~N} 1$ & $11(55)$ & $9(45)$ & 0.81 \\
\hline & Influenza A & $3(15)$ & $4(20)$ & \\
\hline & Others & $6(30)$ & $7(35)$ & \\
\hline \multicolumn{2}{|c|}{ Braden risk score (mean $\pm S D$ ) } & $12.7 \pm 3.0$ & $12.6 \pm 4.3$ & 0.06 \\
\hline \multicolumn{2}{|c|}{ Cycles of proning, median } & $1(1,7)$ & $1(1,11)$ & \\
\hline \multicolumn{2}{|c|}{$\begin{array}{l}\text { Total duration of proning, } \\
\text { hours (mean } \pm \text { SD) }\end{array}$} & $45.7 \pm 43.3$ & $51.4 \pm 43.2$ & 0.98 \\
\hline
\end{tabular}

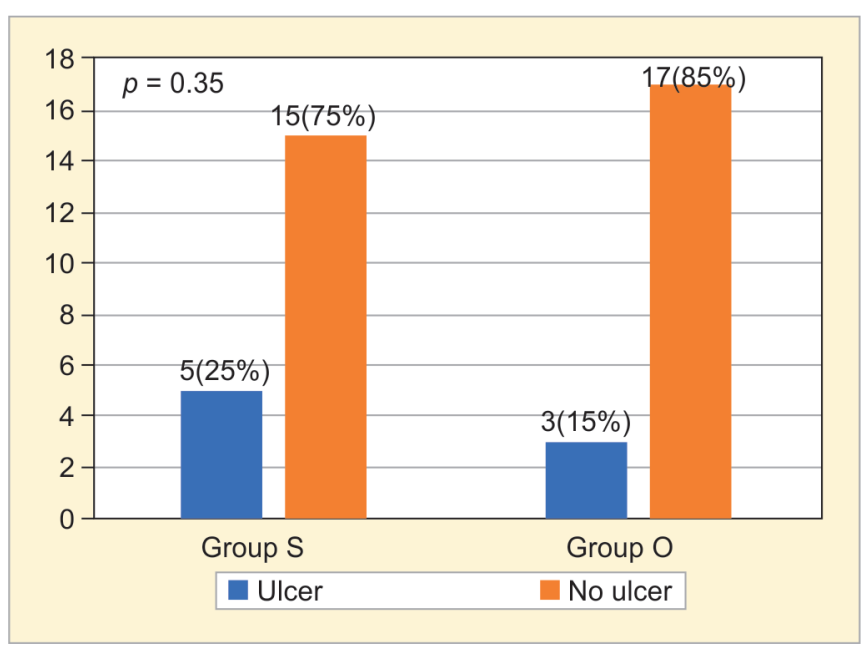

Fig. 1: Incidence of pressure ulcers in patients with different preventive strategies for proning 
$15 \%, p=0.35$ ) (Fig. 1). Chin was the most common site of hospitalacquired pressure ulcer followed by malar prominences. One patient in group $S$ had developed multiple pressure ulcers involving malar prominences, chin, and chest. Both the groups were comparable with regards to tracheostomy, the requirement of extracorporeal membrane oxygenation (ECMO), and 28 -day mortality (30 vs $45 \%$, $p=0.26$ ) (Table 2). Hemodynamic, oxygenation, and ventilatory parameters were comparable in both the groups (Figs 2 to 5). No invasive line or tube-related complications like blockage, kink, or accidental removal were seen in any of the groups. One case each of acute kidney injury and neuropraxia and two cases of ileus were seen in group $\mathrm{O}$. No other complication was seen in any of the groups.

\section{Discussion}

In this retrospective study of 40 patients, done over a period of 3 years, we compared two pressure ulcer preventive strategies in prone ventilated patients. The observational strategy involved proning only on an air mattress with silicone dressing and gel pads

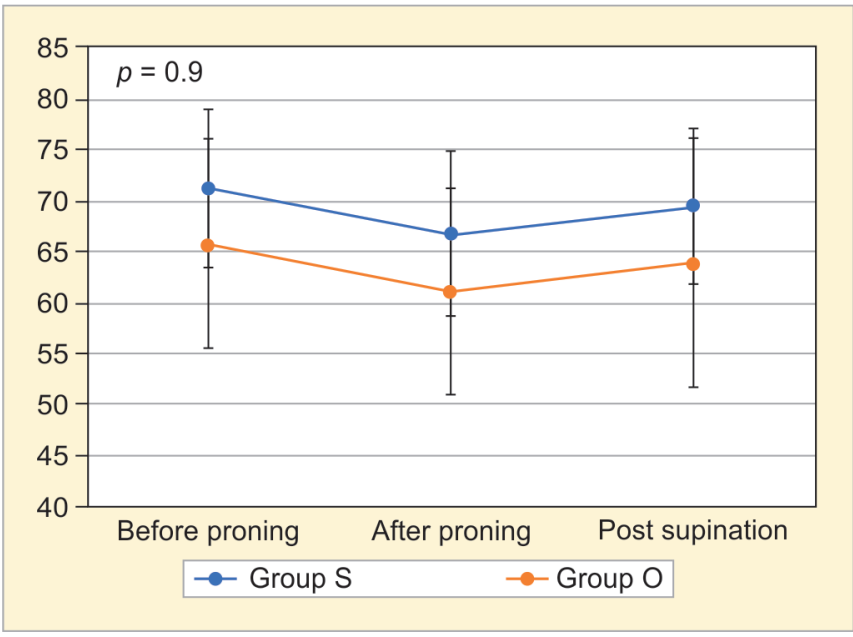

Fig. 2: Changes in mean arterial pressure over time of first proning cycle

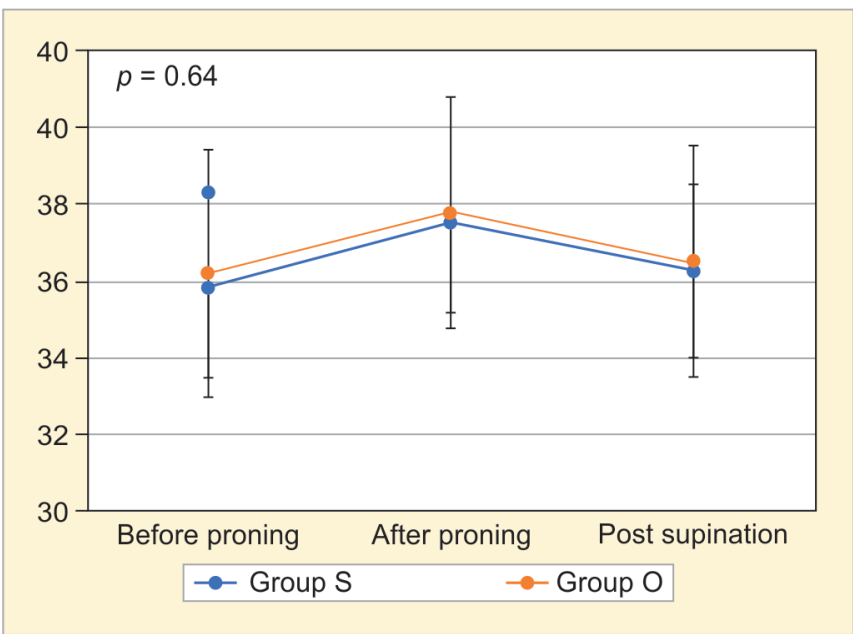

Fig. 4: Changes in peak airway pressure over time during first cycle of proning for pressure points, while the standard strategy involved the use of pillow supports and headrest. The observational preventive strategy was associated with a reduced incidence of hospitalacquired pressure ulcers (15\% compared to $25 \%$ ).

Table 2: Outcome variables

\begin{tabular}{lllll}
\hline Parameters & & $\begin{array}{l}\text { Group S } \\
(n=20)\end{array}$ & $\begin{array}{l}\text { Group O } \\
(n=20)\end{array}$ & p value \\
\hline $\begin{array}{l}\text { Pressure ulcer, } \\
n(\%)\end{array}$ & Ulcer & $5(25)$ & $3(15)$ & 0.35 \\
& No ulcer & $15(75)$ & $17(85)$ & \\
Location, $n$ (\%) & Malar & $3(15)$ & $2(10)$ & \\
& Chin & $2(10)$ & 0 & \\
& Multiple & 0 & $1(5)$ & \\
Stage, $n(\%)$ & I & $4(20)$ & $2(10)$ & \\
& II & $1(5)$ & $1(5)$ & \\
28-day mortality, $n(\%)$ & $6(30)$ & $9(45)$ & 0.26
\end{tabular}

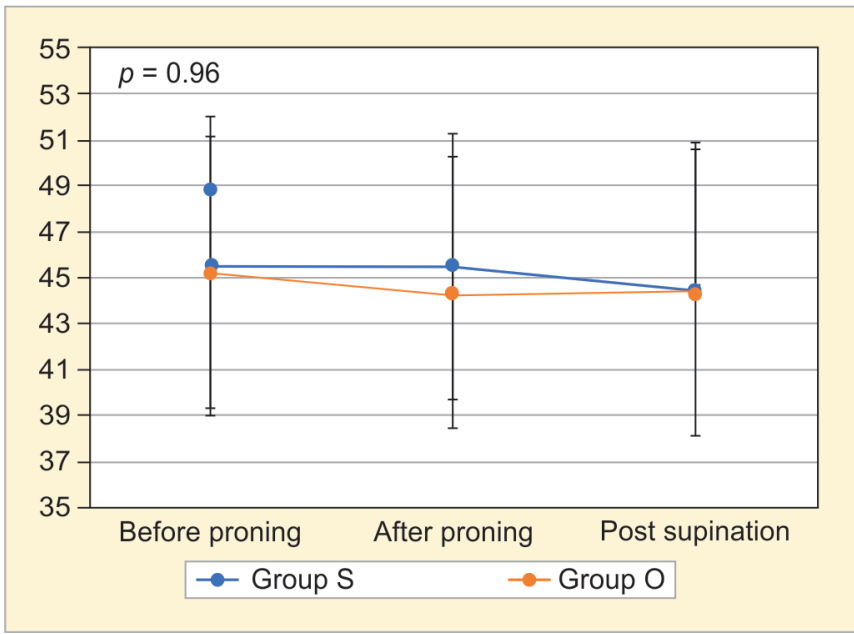

Fig. 3: Changes in partial pressure of $\mathrm{CO}_{2}$ over time during first proning cycle

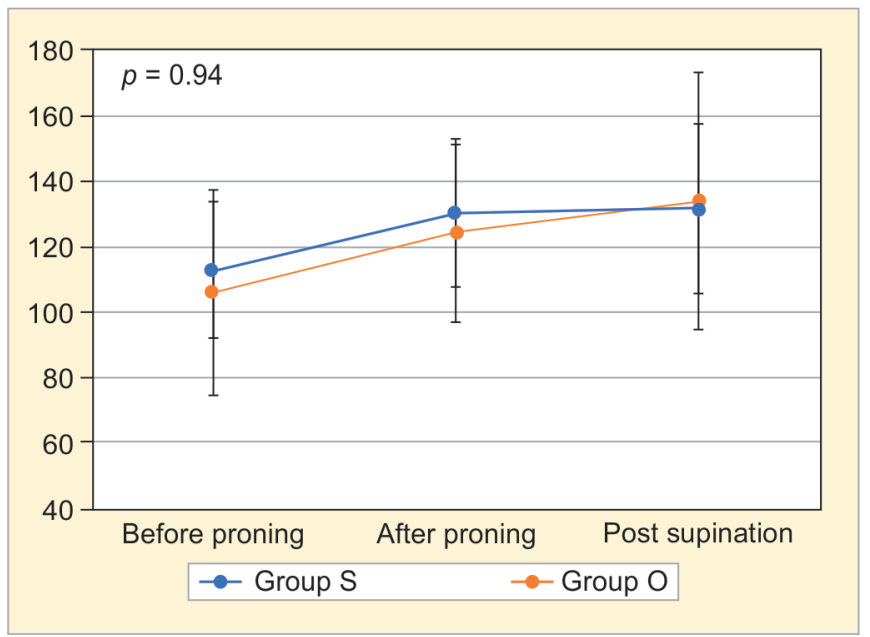

Fig. 5: Changes in $\mathrm{PaO}_{2} / \mathrm{FiO}_{2}$ ratio ( $\mathrm{P} / \mathrm{F}$ ratio) over time during first cycle of proning 
Girard et al., in a randomized control trial done as an ancillary study of the PROSEVA study group, showed an increased likelihood of pressure ulcers in patients undergoing prone positioning. The incidence of hospital-acquired pressure ulcers was 20.80 and $14.26 / 1,000$ intensive care unit (ICU) ventilator days in the prone and supine group, respectively, despite using air mattresses and colloid dressing for the prevention of pressure ulcers. ${ }^{2}$ Studies were done using various preventive strategies like prone head support, automated beds, and polyurethane dressing have shown the incidence of hospital-acquired pressure ulcers in prone patients as high as $65 \% .{ }^{5,6}$ Our study showed an incidence of pressure ulcers of only $15 \%$ with the use of observational strategy.

Yoshimura et al. in a study done on 100 patients in intraoperative setup have shown a reduced incidence of pressure ulcers in prone patients with the use of soft silicone dressing compared with polyurethane dressing (11 vs $3, p=0.027) .{ }^{10}$ Combined use of air mattresses and soft silicone dressing has reduced the incidence of pressure ulcers in our study, though it has failed to reach statistical significance. This can be attributed to a smaller patient population. A similar study when done on a larger patient population may show better results. Also, a difference of $10 \%$ though not statistically significant, may be considered clinically significant considering patient comfort.

The different pressure ulcer preventive strategies did not show any significant difference in the oxygenation, ventilation, and hemodynamic parameters. Though few other complications were reported in the observation group, no tube or invasive line related mechanical complications were noticed. The observational strategy did not have any effect on the outcome of 28-day mortality.

Being a retrospective study, unavailability and incomplete records limited the number of patients that could be included in the study.

\section{Conclusion}

Use of air mattress and soft silicone dressing instead of pillow supports and headrest reduces the incidence of pressure ulcers in patients with prone ventilation for hypoxic respiratory failure (15 vs $25 \%, p=0.35$ ). This difference, in our opinion, is clinically significant. Albeit, there is no statistical difference in our study, we believe that a larger, well-designed, prospective study will show clinical and statistical difference.

\section{Clinical Significance}

To the best of our knowledge, this is the first study comparing the effect of different pressure ulcer preventive strategies in patients with prone ventilation for hypoxic respiratory failure, especially in an intensive care setting. Reduced incidence of pressure ulcer (will prevent facial scars), improves patient comfort, and will significantly contribute to better patient outcome.

\section{ACKNOWLedgments}

The study was approved by the Institutional Ethics Committee. We would like to acknowledge Dr Ullas Gopalakrishna for his valuable support and guidance. We would like to declare that no source of funding was obtained for the study.

\section{Manufacturer Name}

Mepilex ${ }^{\circledast}$ Border (Mölnlycke Health Care, Gothenburg, Sweden).

\section{References}

1. Guérin C, Reignier J, Richard J-C, et al. Prone positioning in severe acute respiratory distress syndrome. N Eng J Med 2013;368(23):21592168. DOI: 10.1056/NEJMoa1214103.

2. Gattinoni L, Tognoni G, Pesenti A, et al. Effect of prone positioning on the survival of patients with acute respiratory failure. $\mathrm{N}$ Engl J Med 2001;345(8):568-573. DOI: 10.1056/NEJMoa010043.

3. Girard R, Baboi L, Ayzac L, et al. The impact of patient positioning on pressure ulcers in patients with severe ARDS: results from a multicentre randomised controlled trial on prone positioning. Intensive Care Med 2014;40:397-403.

4. Rowe C. Development of clinical guidelines for prone positioning in critically ill adults. Nurs Crit Care 2004;9(2):50-57. DOI: 10.1111/j.14785153.2003.0054.x.

5. Bajwa AA, Arasi L, Canabal JM, et al. Automated prone positioning and axial rotation in critically III, nontrauma patients with acute respiratory distress syndrome (ARDS). J Intensive Care Med 2010;25:121-125.

6. Prebio M, Katz-Papatheophilou E, Heindl W, et al. Reduction of pressure sores during prone positioning of ventilated intensive care patients by the prone-head support system: a pilot study. Wien Klin Wochenschr 2005;117:98-105.

7. Kim RS, Mullins K. Preventing facial pressure ulcers in acute respiratory distress syndrome (ARDS). J Wound Ostomy Continence Nurs 2016;43:427-429.

8. Lee $\mathrm{W}-\mathrm{Y}$, Lin $\mathrm{P}-\mathrm{C}$, Weng $\mathrm{C}-\mathrm{H}$, et al. A project to reduce the incidence of facial pressure ulcers caused by prolonged surgery with prone positioning. Hu Li Za Zhi 2012;59:70-78.

9. Nixon J, Smith IL, Brown S, et al. Pressure relieving support surfaces for pressure ulcer prevention (PRESSURE 2): clinical and health economic results of a randomised controlled trial. E Clin Med 2019;14:42-52.

10. Yoshimura M, Ohura N, Tanaka J, et al. Soft silicone foam dressing is more effective than polyurethane film dressing for preventing intraoperatively acquired pressure ulcers in spinal surgery patients: the border operating room spinal surgery (BOSS) trial in Japan. Int Wound J 2018;15:188-197.

11. Edsberg LE, Black JM, Goldberg M, et al. Revised national pressure ulcer advisory panel pressure injury staging system. JWound Ostomy Continence Nurs 2016;43:585-597. 